\title{
Effects of Two Identical Notches in the Same and Opposite Non Radiating Edges of a Rectangular Microstrip Patch Antenna
}

\author{
Sunandan Bhunia ${ }^{1}$, Avisankar Roy ${ }^{2}$, Debasree Chanda Sarkar $^{3}$ and \\ Partha Pratim Sarkar ${ }^{4}$ \\ ${ }^{1}$ Central Institute of Technology, Kokrajhar, Assam, India \\ ${ }^{2}$ Haldia Institute of Technology, Haldia, Purba Medinipur, West Bengal, India \\ ${ }^{3,4}$ DETS, University of Kalyani, Kalyani, Nadia, West Bengal, India \\ ${ }^{1}$ snb.hit@gmail.com, ${ }^{2}$ avisankar.roy@gmail.com, ${ }^{3}$ dsarkar70@gmail.com, \\ ${ }^{4}$ parthabe91@yahoo.co.in
}

\begin{abstract}
In this paper the effects of two identical notches in the same non radiating edge and opposite non radiating edges have been studied extensively. The effect on resonant frequency and gain with the variation of the notch length and notch width are studied. It has been observed that the notches in the opposite non radiating edges affect more on resonant frequency than the notches in the same non radiating edge of a microstrip patch antenna. About $80.2 \%$ size reduction has been achieved by the dual notches in the same non radiating edge and about $87.5 \%$ size reduction is achieved for the dual notches in the opposite non radiating edges.
\end{abstract}

Keywords: Microstrip patch antenna, notch, radiating edge, non-radiating edge

\section{Introduction}

Due to different attractive features of microstrip patch antenna like low profile, light weight, easy fabrication, conformal to mount structures etc., microstrip patch antennas (MPA) are very popular in modern communication systems [1] though they suffer mainly from two serious limitations one is low gain and the other is narrow bandwidth. To overcome these limitations several approaches are made in different research articles. Along with overcoming the main two limitations in current research significant emphasis have been taken to use microstrip patch antennas in portable devices utilizing the advantages of them [2]. As a result, there has been taken considerable efforts in many literatures to reduce the antenna size. But reduction in size of the antenna impacts adversely on the antenna parameters like return loss, bandwidth, resonant frequency, radiation efficiency, gain etc. Many researchers have used different techniques to design compact microstrip patch antenna. S. Bhunia et al., [3-4] has investigated on compactness and multi frequency operation of microstrip patch antenna cutting rectangular slots on the patch and almost $85 \%$ size reduction is reported. Size reduction by slot loading in the radiating patch of the microstrip patch antenna has also been reported in the literature [5-7]. A. Roy et al., [8-9] has investigated on compactness of microstrip patch antenna, utilizing spur lines and strip loading to the patch and $87 \%$ size reduction with dual band operation has been reported. Size reduction of the slot antenna using reactive terminations at the ends of the slot was reported in [10]. Size reduction was reported in [11] by loading the slot using series inductive slits. Miniaturization of slot antennas using slit and strip loading was reported in [12]. Some research articles have shown the analysis of the effects of slot cutting on the patch, with equivalent

Received (February 13, 2018), Review Result (May 11, 2018), Accepted (May 15, 2018) 
circuits and theoretical studies [13-19]. A compact dual band rectangular microstrip antenna, realized by two different single slits has been designed in [20]. In this design $53.73 \%$ compactness has been found. S. Mathew et. al., [21] has proposed a compact circular microstrip patch antenna with $\mathrm{V}$ shaped slit and $48 \%$ size reduction has been reported. Some investigations on size reduction by cutting different slots on patch have been carried out in [22-27]. A. A. Deshmukh et al., [28] has discussed the variation of resonant frequency with the variation of slot length and reduced resonant frequency has been validated with current path calculation. Compact microstrip antenna has been designed utilizing meandered strips and rectangular slots on patch with monopole structure and antenna characteristics has been discussed with parametric studies and current distributions in some literatures [2931]. In [31], the resonant frequency has been calculated from the slot length and the results have been validated by simulated current distribution and measured values.

In this paper effects of two identical notches in the same and opposite non-radiating edges of a microstrip patch antennas are extensively studied. The antennas for the best results are fabricated and the simulated \& measured results are compared. The measured results are well agreed with the simulated results.

\section{Antenna Design Concept}

The configuration of the reference antenna (Antenna 1) resonating at frequency $f_{r}=$ $10 \mathrm{GHz}$ is shown in Figure 1. The length $(L=9 \mathrm{~mm})$ and width $(W=12 \mathrm{~mm})$ of Antenna 1 have been calculated from conventional rectangular microstrip patch antenna design equations. The substrate (Arlon AD300A) with dielectric constant $\varepsilon_{r}=2.2$, loss tangent $\tan \delta=0.002$ and thickness $h=1.5875 \mathrm{~mm}$ has been taken for this design. The dimensions of the ground plane have been taken as more than three times of the patch size as if it behaves as an infinite ground plane, and the antenna has been fed by a coaxial cable at optimum location to achieve the impedance very close to the characteristic impedance of

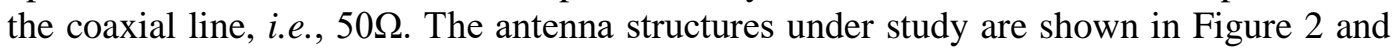
Figure 3. In Figure 2 the rectangular notches are in the same non radiating edge and in Figure 3 the rectangular notches are in the opposite non radiating edge. All the relevant parameters of the antenna structures under study are shown in Figure $2 \&$ Figure 3.

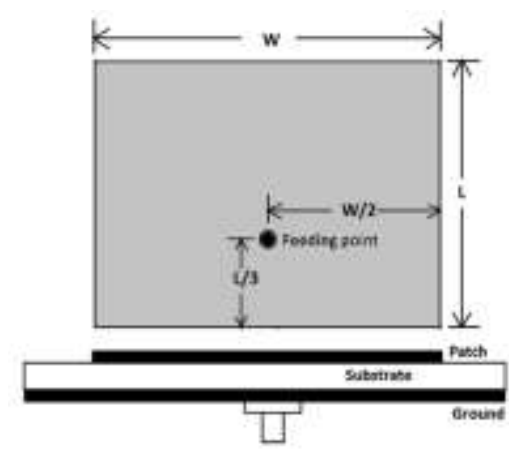

Figure 1. Reference Antenna (Antenna 1) Configuration

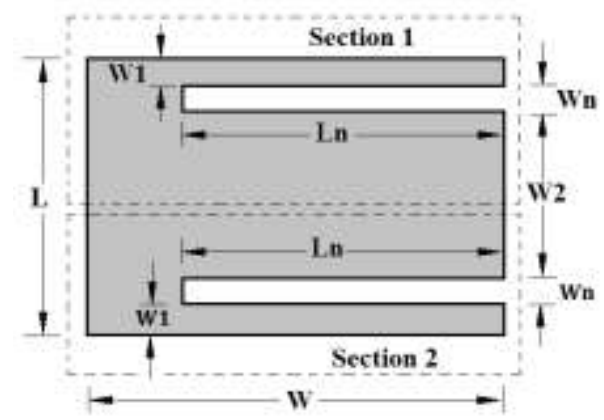

Figure 2. Antenna 2 Configuration 


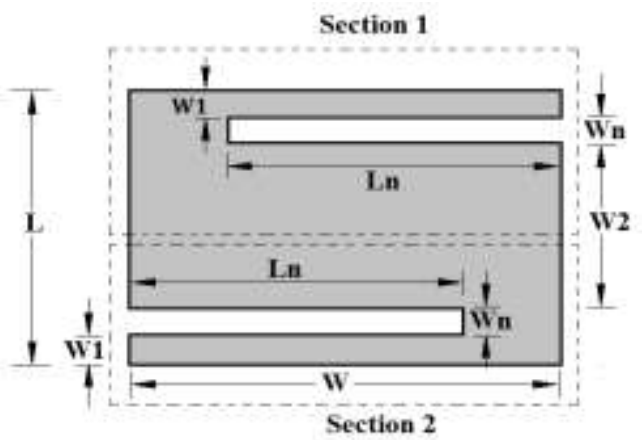

Figure 3. Antenna 3 Configuration

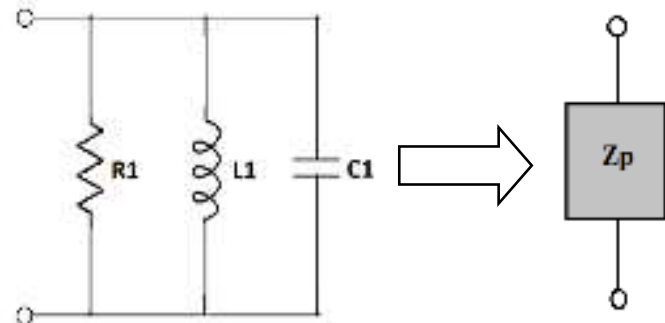

Figure 4. Equivalent Circuit of the Patch of Section 1 or 2 without Notch

\section{Theoretical Formulation and Equivalent Circuit}

The microstrip patch antenna under study can be treated as the combination of two sections i.e., Section 1 and Section 2. Section 1 and Section 2 both are identical notch loaded microstrip patch antenna with patch dimension $W \times \frac{L}{2}$ and notch dimension $W_{n} \times$ $L_{n}$. The equivalent circuit of the patch of either section 1 or section 2 without notch is the parallel combination of resistance $\left(R_{l}\right)$, inductance $\left(L_{l}\right)$ and capacitance $\left(C_{l}\right)$. The equivalent circuit of the patch can be modelled as shown in Figure 4.

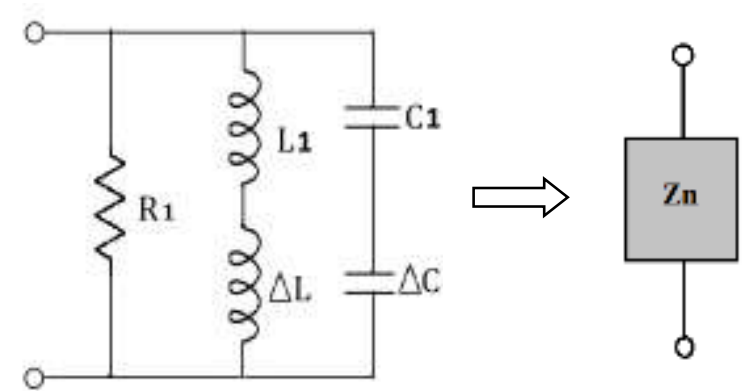

Figure 5. Equivalent Circuit due to the Effect of Notch

Where $R_{1}, L_{1}, C_{1}$ can be defined as [16]

$$
\begin{aligned}
C_{1} & =\frac{\epsilon_{0} \epsilon_{e f f} L W}{2 h} \operatorname{Cos}^{-2}\left(\frac{\pi y_{0}}{L}\right), \\
L_{1} & =\frac{1}{\omega^{2} C_{1}}, \\
R_{1} & =\frac{Q_{r}}{\omega c_{1}},
\end{aligned}
$$

Where $L$ and $W$ are the length and width of the rectangular patch antenna and $h$ is the thickness of the dielectric substrate of effective permittivity $\epsilon_{e f f}$.

$Q_{r}=\frac{C \sqrt{\epsilon_{\text {reff }}}}{4 f h}$ and $\epsilon_{\text {reff }}=\frac{\epsilon_{r}+1}{2}+\frac{\epsilon_{r}-1}{2}\left(1+12 \frac{h}{W}\right)^{-\frac{1}{2}}$; Where the symbols have their usual meanings.

When a notch is incorporated in a patch two currents are flowing in the patch one is the normal current and the other is the current around the notch. Due to insertion of the notch in a patch discontinuities occur for magnetic field as well as electric field both which can 
be modeled as an additional inductance $\Delta L$ and additional capacitance $\Delta C$ with the existing inductance and capacitance of the equivalent circuit of the patch [10] shown in Figure 5.

The additional inductance $\Delta L$ can be written as [17-18],

$$
\Delta L=\frac{Z_{1}+Z_{2}}{16 \pi f \operatorname{Cos}^{-2}\left(\frac{\pi y_{0}}{L / 2}\right)} \tan \left(\frac{\pi f L_{n}}{c}\right)
$$

where

$$
\begin{aligned}
& Z_{1}=\frac{120 \pi / \sqrt{\epsilon_{\text {reff }}}}{\left(\frac{W_{1}}{h}\right)+1.393+0.667 \ln \left(\frac{W_{1}}{h}+1.444\right)} \\
& Z_{2}=\frac{120 \pi / \sqrt{\epsilon_{\text {reff }}}}{\left(\frac{W_{2}}{2 h}\right)+1.393+0.667 \ln \left(\frac{W_{2}}{2 h}+1.444\right)}
\end{aligned}
$$

The capacitance $\Delta C$ is calculated as gap capacitance by [17]

$\Delta C=2\left(L_{n}\right) \frac{\epsilon_{0}}{\pi}\left[\ln \left(2 \frac{1+\sqrt{k^{\prime}}}{1-\sqrt{k^{\prime}}}\right)+\ln \operatorname{Coth}\left(\frac{\pi W_{n}}{4 h}\right)+0.013 C_{f} \frac{h}{W_{n}}\right] \operatorname{Cos}^{2}\left(\frac{\pi y_{0}}{L}\right)$

where $k^{\prime}=\sqrt{1-k^{2}}, k^{2}=\frac{1+\frac{W_{1}}{W_{n}}+\frac{W_{2}}{W_{n}}}{\left(1+\frac{W_{1}}{W_{n}}\right)\left(1+\frac{W_{2}}{W_{n}}\right)}$

$C_{f}$ is the fringe capacitance [14] and is given by

$$
C_{f}=\frac{1}{2}\left[\frac{\sqrt{\epsilon_{r e f f}}}{c Z_{0}}-\epsilon_{0} \epsilon_{r} \frac{W}{h}\right],
$$

$Z_{0}$ is the characteristic impedance of the microstrip patch.

The equivalent circuit of section 1 or section 2 with notch loaded can be modeled as shown in Figure 6.

The value of the coupling capacitor $C_{c}$ is defined as [17]

$$
C_{c}=\frac{-\left(C_{1}+C_{2}\right)+\sqrt{\left(\left(C_{1}+C_{2}\right)^{2}-4 C_{1} C_{2}\left(1-\frac{1}{C_{p}^{2}}\right)\right)}}{2},
$$

Where $C_{2}=C_{1}+\Delta C$ and $C_{p}$ is the coupling factor [17]

The designed antenna of Figure 2 can be modeled as a combination of Section 1 and Section 2 side by side in back to back termination and the designed antenna of Figure 3 can be modeled as the combination of Section 1 and Section 2 side by side but in back to front termination. The equivalent circuit of designed antenna shown in Figure 2 can be drawn in conventional way as, the parallel combination of equivalent circuit of notch loaded Section $1 \& 2$, shown in Figure 7. The equivalent circuit of designed antenna shown in Figure 3 can be drawn as, the series combination of equivalent circuit of notch loaded Section $1 \& 2$, shown in Figure 8.

The total input impedance $Z_{T}$ can be easily found out from the equivalent circuit shown in Figure 7 and Figure 8. The proposed antenna is fed with a co-axial cable of characteristic impedance $Z_{0}=50 \Omega$. After finding the total input impedance $Z_{T}$ one can easily find out the reflection co-efficient, VSWR, and return loss [18].

Reflection coefficient, $\Gamma=\frac{Z_{0}-Z_{T}}{Z_{0}+Z_{T}}$,

$\operatorname{VSWR}=\frac{1+|\Gamma|}{1-|\Gamma|}$, 
Return $\operatorname{Loss} R_{L}=20 \log |\Gamma|$

The radiation pattern $E_{\theta}$ and $E_{\varnothing}$ can also be easily found out using the well-known formula [18].

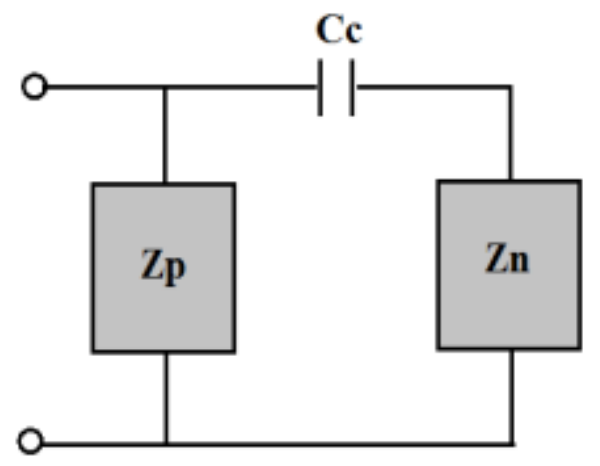

Figure 6. Equivalent Circuit of Notch Loaded Section 1 or Section 2

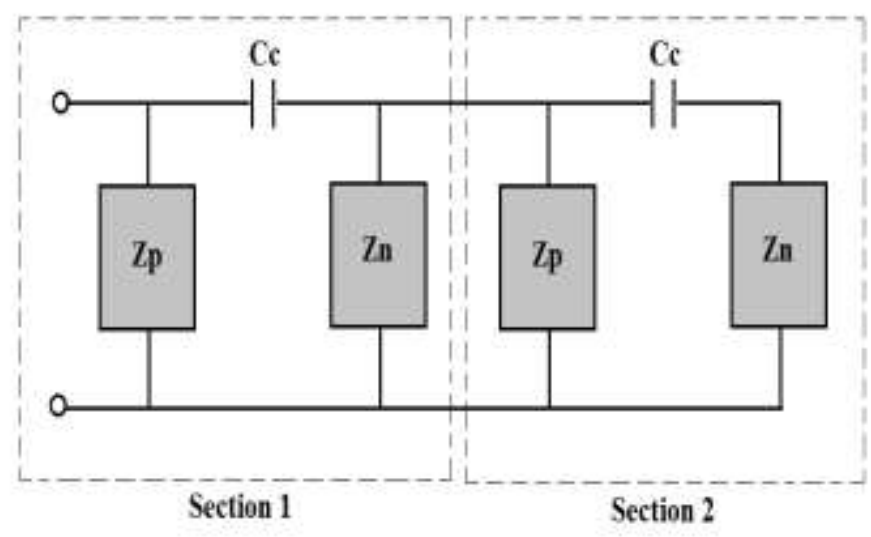

Figure 7. Equivalent Circuit of Antenna 2

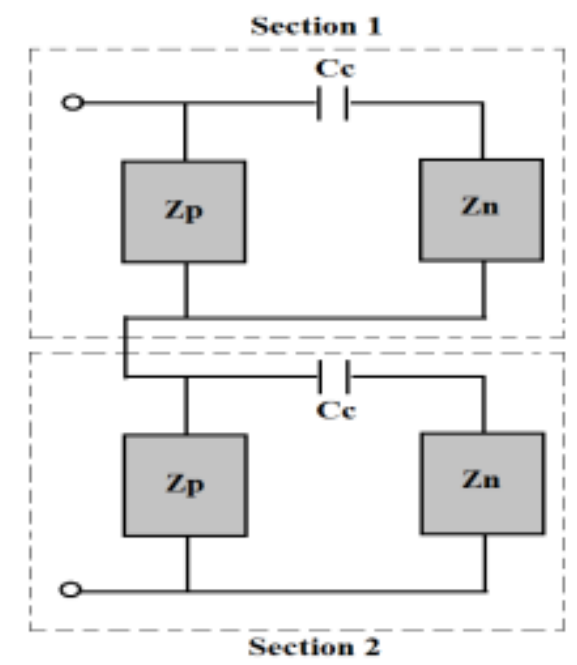

Figure 8. Equivalent Circuit of Antenna 3 


\section{Parametric Study}

To achieve the dimension of the final designed antenna extensive parametric studies have been carried out. The simulated results of the designed antenna with the variation of notch dimensions i.e., $W_{n}$ and $L_{n}$ are shown in Table 1 to Table 6 . The graph for variation of resonant frequency with notch length $\left(L_{n}\right)$ and variation of gain with notch length $\left(L_{n}\right)$ have been shown in Figure 9.

Table 1. Variation of Antenna Characteristics with $L_{n}(m m)$ where $W_{n}=$ $1 \mathrm{~mm}$

\begin{tabular}{|c|c|c|c|c|c|c|}
\hline \multirow{2}{*}{$\begin{array}{c}\text { Notch } \\
\text { length } \\
\boldsymbol{L}_{\boldsymbol{n}}(\mathbf{m m})\end{array}$} & \multicolumn{3}{|c|}{ Notches are in same edge } & \multicolumn{3}{c|}{ Notches are in opposite edges } \\
\cline { 2 - 7 } & $\begin{array}{c}\text { Resonant } \\
\text { frequency } \\
\boldsymbol{f}_{\boldsymbol{r}}(\boldsymbol{G H z})\end{array}$ & $\begin{array}{c}\text { Return } \\
\text { Loss } \\
(\mathbf{d B})\end{array}$ & $\begin{array}{c}\text { Gain } \\
(\mathbf{d B i})\end{array}$ & $\begin{array}{c}\text { Resonant } \\
\text { frequency } \\
\boldsymbol{f}_{\boldsymbol{r}}(\boldsymbol{G H z})\end{array}$ & $\begin{array}{c}\text { Return } \\
\text { Loss } \\
(\mathbf{d B})\end{array}$ & $\begin{array}{c}\text { Gain } \\
(\mathbf{d B i})\end{array}$ \\
\hline 1 & 7.752 & 25.66 & 4.3 & 7.718 & 38.23 & 3.7 \\
\hline 2 & 7.749 & 11.08 & 4.2 & 7.576 & 19.28 & 3.5 \\
\hline 3 & 7.681 & 15.27 & 4 & 7.449 & 21.2 & 3.2 \\
\hline 4 & 7.583 & 13.01 & 4 & 7.339 & 17.84 & 3.5 \\
\hline 5 & 7.508 & 10.78 & 3.7 & 6.721 & 15.94 & 3.6 \\
\hline 6 & 7.111 & 17.12 & 3.3 & 6.439 & 16.34 & 3.7 \\
\hline 7 & 6.406 & 13.89 & 3.6 & 6.182 & 20.56 & 3.6 \\
\hline 8 & 5.782 & 11.48 & 3.4 & 5.542 & 26.91 & 3.2 \\
\hline 9 & 5.269 & 21.9 & 3.5 & 5.013 & 11.84 & 3.1 \\
\hline 10 & 4.805 & 15.59 & 3.5 & 4.565 & 17.24 & 3.1 \\
\hline
\end{tabular}

Table 2. Variation of Antenna Characteristics with $L_{n}(\mathrm{~mm})$ where $W_{n}=$ $2 m m$

\begin{tabular}{|c|c|c|c|c|c|c|}
\hline \multirow{2}{*}{$\begin{array}{c}\text { Notch } \\
\text { length } \\
\boldsymbol{L}_{\boldsymbol{n}}(\mathbf{m m})\end{array}$} & \multicolumn{2}{|c|}{ Notches are in same edge } & \multicolumn{3}{c|}{ Notches are in opposite edges } \\
\cline { 2 - 7 } & $\begin{array}{c}\text { Resonant } \\
\text { frequency } \\
\boldsymbol{f}_{\boldsymbol{r}}(\boldsymbol{G H z})\end{array}$ & $\begin{array}{c}\text { Return } \\
\text { Loss } \\
(\mathbf{d B})\end{array}$ & $\begin{array}{c}\text { Gain } \\
(\mathbf{d B i})\end{array}$ & $\begin{array}{c}\text { Resonant } \\
\text { frequency } \\
\boldsymbol{f}_{\boldsymbol{r}}(\boldsymbol{G H z})\end{array}$ & $\begin{array}{c}\text { Return } \\
\text { Loss } \\
(\mathbf{d B})\end{array}$ & $\begin{array}{c}\text { Gain } \\
(\mathbf{d B i})\end{array}$ \\
\hline 1 & 7.721 & 20.01 & 4.2 & 7.716 & 14.33 & 3.6 \\
\hline 2 & 7.701 & 11.76 & 4 & 7.493 & 18.92 & 3.5 \\
\hline 3 & 7.601 & 15.76 & 3.7 & 7.391 & 21.1 & 3.1 \\
\hline 4 & 7.489 & 12.51 & 3.9 & 7.339 & 11.98 & 3.2 \\
\hline 5 & 7.403 & 11.89 & 3.2 & 6.641 & 11.81 & 3 \\
\hline 6 & 6.743 & 21 & 3.5 & 6.294 & 12.86 & 2.7 \\
\hline 7 & 6.102 & 31.08 & 3 & 5.606 & 17.74 & 2.5 \\
\hline 8 & 5.526 & 25.38 & 3.3 & 5.029 & 17.47 & 3 \\
\hline 9 & 5.029 & 18.66 & 3.2 & 4.549 & 14.59 & 2.1 \\
\hline 10 & 4.565 & 13.19 & 3 & 4.148 & 10.64 & 2 \\
\hline
\end{tabular}


Table 3. Variation of Antenna Characteristics with $L_{n}(m m)$ where $W_{n}=$ $3 m m$

\begin{tabular}{|c|c|c|c|c|c|c|}
\hline \multirow{2}{*}{$\begin{array}{c}\text { Notch } \\
\text { length }\end{array}$} & \multicolumn{2}{|c|}{ Notches are in same edge } & \multicolumn{3}{c|}{ Notches are in opposite edges } \\
\cline { 2 - 7 }$(\mathbf{m m})$ & $\begin{array}{c}\text { Resonant } \\
\text { frequency } \\
\boldsymbol{f}_{\boldsymbol{r}}(\boldsymbol{G H z})\end{array}$ & $\begin{array}{c}\text { Return } \\
\text { Loss } \\
(\mathbf{d B})\end{array}$ & $\begin{array}{c}\text { Gain } \\
(\mathbf{d B i})\end{array}$ & $\begin{array}{c}\text { Resonant } \\
\text { frequency } \\
\boldsymbol{f}_{\boldsymbol{r}}(\boldsymbol{G H z})\end{array}$ & $\begin{array}{c}\text { Return } \\
\text { Loss } \\
(\mathbf{d B})\end{array}$ & $\begin{array}{c}\text { Gain } \\
(\mathbf{d B i})\end{array}$ \\
\hline 1 & 7.703 & 11.76 & 3.7 & 7.656 & 15.29 & 3 \\
\hline 2 & 7.686 & 18.56 & 4 & 7.433 & 12.69 & 2.5 \\
\hline 3 & 7.541 & 15.78 & 3.6 & 7.294 & 11.92 & 2.7 \\
\hline 4 & 7.389 & 20.01 & 3.9 & 7.239 & 10.1 & 3 \\
\hline 5 & 7.292 & 10.57 & 3 & 6.583 & 27.27 & 2.5 \\
\hline 6 & 6.567 & 21.35 & 2.9 & 5.75 & 10.2 & 2 \\
\hline 7 & 5.942 & 29.25 & 3.2 & 5.061 & 12.21 & 2 \\
\hline 8 & 5.381 & 13.2 & 2.8 & 4.501 & 15.03 & 1.5 \\
\hline 9 & 4.901 & 10.47 & 2.7 & 4.068 & 13.22 & 1.3 \\
\hline 10 & 4.452 & 10.12 & 2.8 & 3.716 & 10.43 & 1 \\
\hline
\end{tabular}

Table 4. Variation of Antenna Characteristics with $L_{n}(\mathrm{~mm})$ where $W_{n}=$ 3. $5 \mathrm{~mm}$

\begin{tabular}{|c|c|c|c|c|c|c|}
\hline \multirow{2}{*}{$\begin{array}{c}\text { Notch } \\
\text { length } \\
\boldsymbol{L}_{\boldsymbol{n}}(\mathbf{m m})\end{array}$} & \multicolumn{2}{|c|}{ Notches are in same edge } & \multicolumn{3}{c|}{ Notches are in opposite edges } \\
\cline { 2 - 7 } & $\begin{array}{c}\text { Resonant } \\
\text { frequency } \\
\boldsymbol{f}_{\boldsymbol{r}}(\boldsymbol{G H z})\end{array}$ & $\begin{array}{c}\text { Return } \\
\text { Loss } \\
(\mathbf{d B})\end{array}$ & $\begin{array}{c}\text { Gain } \\
(\mathbf{d B i})\end{array}$ & $\begin{array}{c}\text { Resonant } \\
\text { frequency } \\
\boldsymbol{f}_{\boldsymbol{r}}(\boldsymbol{G H z})\end{array}$ & $\begin{array}{c}\text { Return } \\
\text { Loss } \\
(\mathbf{d B})\end{array}$ & $\begin{array}{c}\text { Gain } \\
(\mathbf{d B i})\end{array}$ \\
\hline 1 & 7.689 & 12.76 & 3.5 & 7.495 & 12.39 & 2 \\
\hline 2 & 7.66 & 17.21 & 3.1 & 7.341 & 15.29 & 1.7 \\
\hline 3 & 7.503 & 10.57 & 3 & 7.294 & 14.81 & 1 \\
\hline 4 & 7.307 & 13.89 & 2.7 & 7.143 & 12.31 & 0.5 \\
\hline 5 & 7.239 & 31.02 & 3.2 & 6.342 & 16.1 & 0.7 \\
\hline 6 & 6.519 & 18.13 & 3 & 5.477 & 14.44 & 1 \\
\hline 7 & 5.894 & 32.17 & 2.6 & 4.709 & 15.81 & 0 \\
\hline 8 & 5.349 & 18.89 & 2.7 & 4.148 & 12.1 & 0.7 \\
\hline 9 & 4.869 & 12.53 & 2.6 & 3.748 & 18.51 & -0.5 \\
\hline 10 & 4.42 & 20 & 2.5 & 3.427 & 15 & -0.5 \\
\hline
\end{tabular}

It has been seen from the simulated results that resonant frequency decreases with the increase of the notch length or width irrespective of the notch position which is quite obvious as the increased notch dimensions disturbed current lines more. This meandered current lines increase the equivalent current length on the patch and as a result reduction of frequency occurs. Again when the notch dimensions are increases the radiating patch area decreases which results of decrease in gain. But it is interesting to note that along with notch dimension the notch position is also very important. Simulated results show that notches are in opposite non-radiating edges has more effect on resonant frequency and gain than the notches are in the same non radiating edge. 


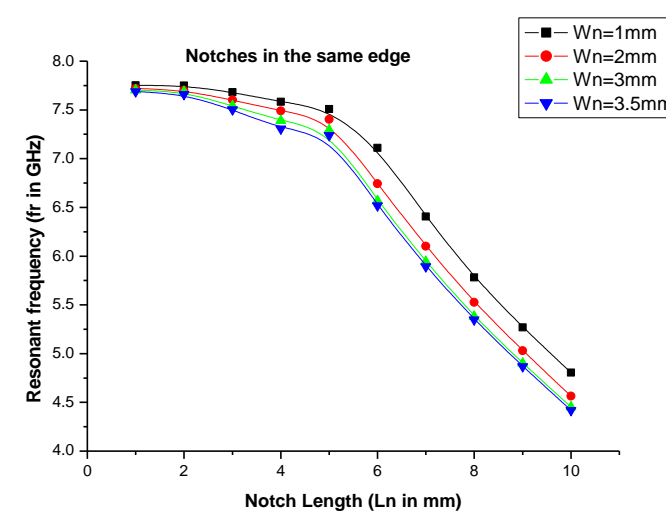

(a)

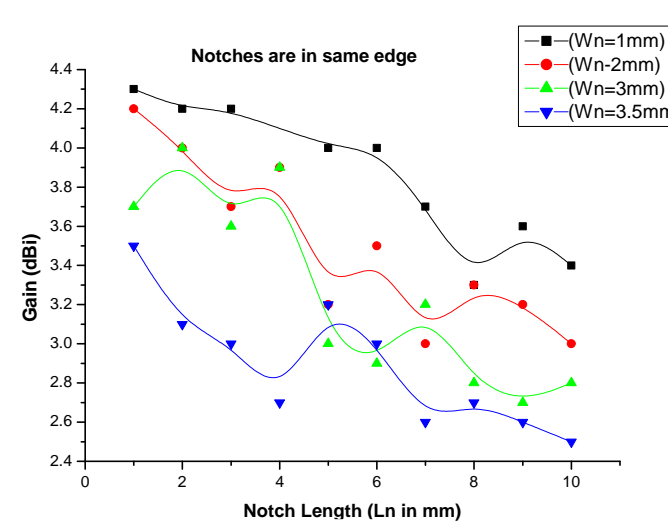

(c)

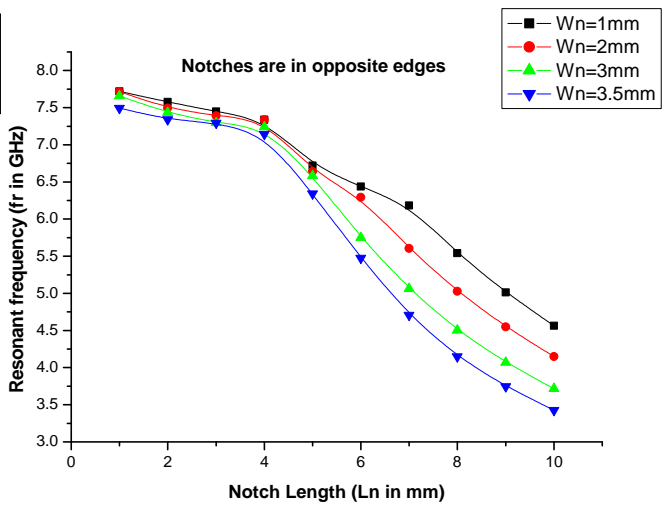

(b)

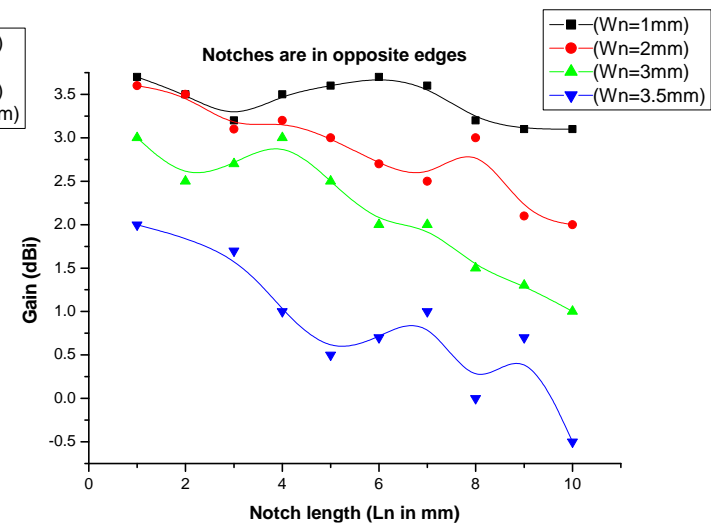

(d)

Figure 9. Variation of Resonant Frequency with Notch Length for (a) Antenna with Notches in same Edge, (b) Antenna with Notches in Opposite Edge, and Variation of Gain with Notch Length for (c) Antenna with Notches in same Edge, (d) Antenna with Notches in Opposite Edge

\section{Results and Discussion}

The reference antenna Antenna1 and the designed antenna Antenna2 (with $W_{n}=$ $3.5 \mathrm{~mm}, L_{n}=10 \mathrm{~mm}$ ) \& Antenna 3 (with $W_{n}=3.5 \mathrm{~mm}, L_{n}=10 \mathrm{~mm}$ ) are fabricated which is shown in Figure 10 and the measured results are compared with the simulated results. The measured results have been agreed very well with the simulated results. The simulated and measured results are shown in Table 5 and frequency vs return loss graphs of reference antenna, Antenna 2 and Antenna 3 are shown in Figure 11.

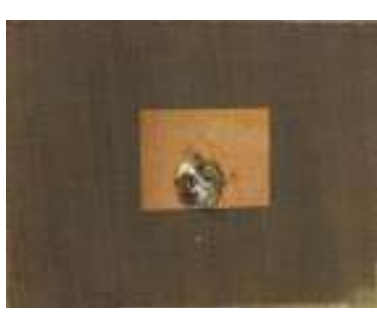

(a)

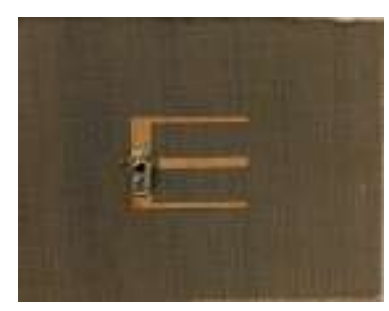

(b)

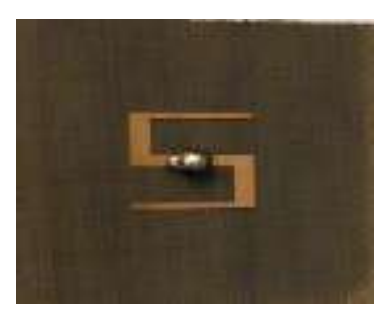

(c)

Figure 10. Fabricated (a) Reference Antenna (b) Antenna 2 and (c) Antenna 3 
Table 5. Simulated and Measured Results

\begin{tabular}{|c|c|c|c|c|}
\hline \multicolumn{2}{|c|}{ Antenna Structure } & $\begin{array}{c}\text { Reference } \\
\text { Antenna 1 }\end{array}$ & Antenna 2 & Antenna 3 \\
\hline \multirow{3}{*}{$\begin{array}{c}\text { Simulated } \\
\text { results }\end{array}$} & Resonant frequency (GHz) & 9.8 & 4.4 & 3.4 \\
\cline { 2 - 5 } & Return Loss(dB) & 16 & 20 & 15 \\
\cline { 2 - 5 } & Bandwidth (MHz, \%) & $520,5.3$ & $100,2.3$ & $80,2.4$ \\
\cline { 2 - 5 } & Gain (dBi) & 5.6 & 2.5 & -0.5 \\
\hline \multirow{3}{*}{$\begin{array}{c}\text { Measured } \\
\text { results }\end{array}$} & Resonant frequency (GHz) & 9 & 4.6 & 3.7 \\
\cline { 2 - 5 } & Return Loss(dB) & 30 & 28 & 20 \\
\cline { 2 - 5 } & Bandwidth (MHz, \%) & $500,5.5$ & $200,4.3$ & $200,4.3$ \\
\cline { 2 - 5 } & Gain (dBi) & 6 & 3 & 0.2 \\
\hline
\end{tabular}

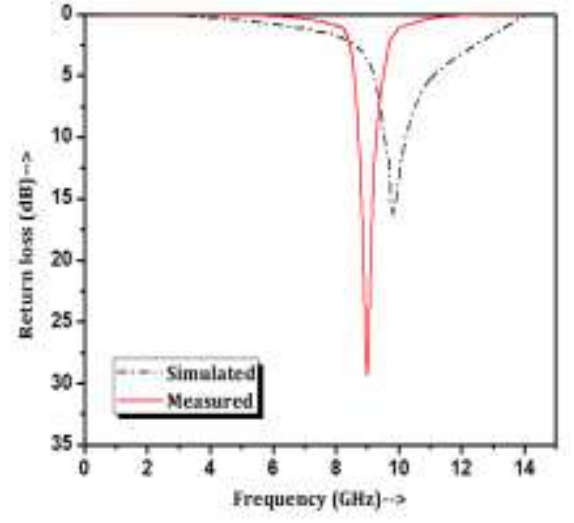

(a)

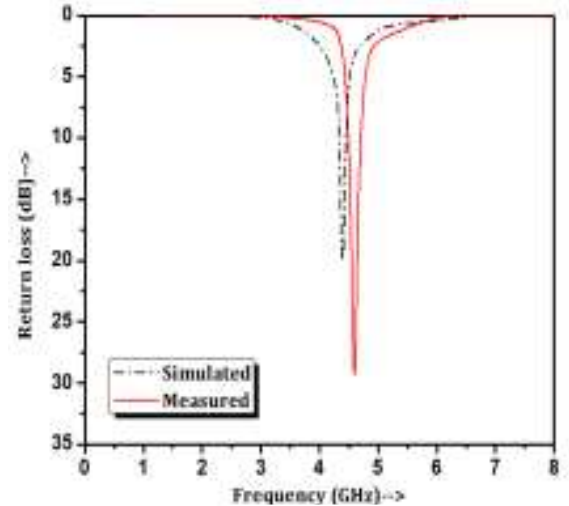

(b)

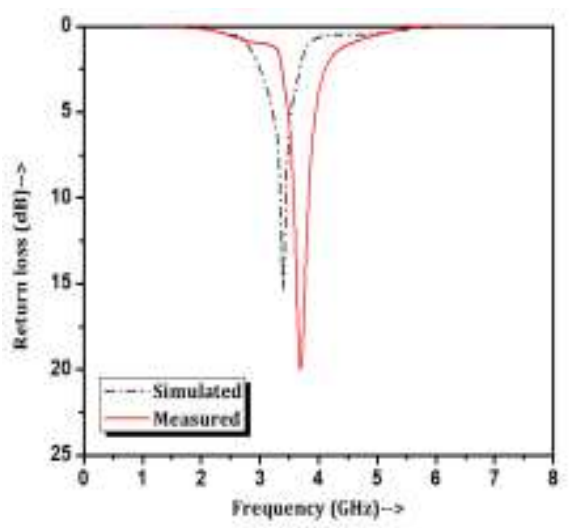

(c)

Figure 11. Simulated and Measured Frequency vs Return Loss Graphs for (a) Reference Antenna, (b) Antenna 2 and (c) Antenna 3

The measured resonant frequency of reference antenna has been found as $9 \mathrm{GHz}$ with $30 \mathrm{~dB}$ return loss and $6 \mathrm{dBi}$ gain. Antenna 2 and Antenna 3 resonates at $4.6 \mathrm{GHz}$ with $28 \mathrm{~dB}$ return loss and $3.7 \mathrm{GHz}$ with $20 \mathrm{~dB}$ return loss as per measured results. The measured gains for Antenna 2 and Antenna 3 have been found as $3 \mathrm{dBi}$ and $0.2 \mathrm{dBi}$ respectively.

The current distribution on the slotted patch for Antenna 2 and Antenna 3 at $4.4 \mathrm{GHz}$ and $3.4 \mathrm{GHz}$ respectively have been shown in Figure 12. The resonant frequency can be calculated from the current path length as shown in Figure 13 for Antenna 2 and Antenna 3. 


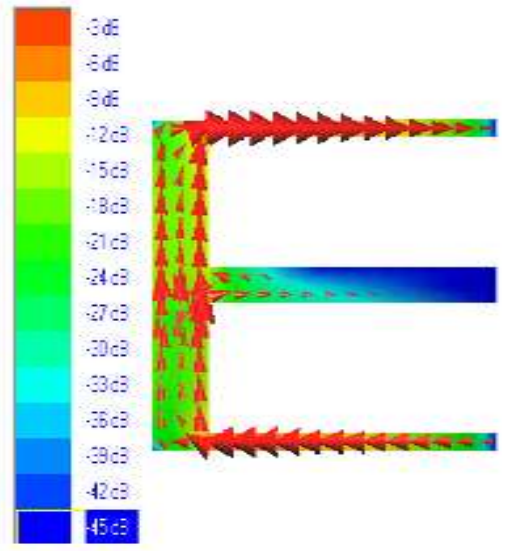

(a)

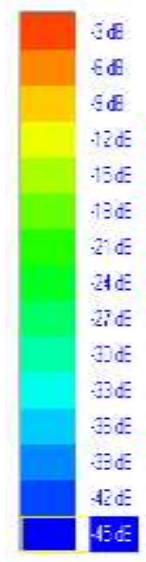

(b)

Figure 12. Current Distribution for (a) Antenna 2 at $4.4 \mathrm{GHz}$ and (b) Antenna 3 at $3.4 \mathrm{GHz}$

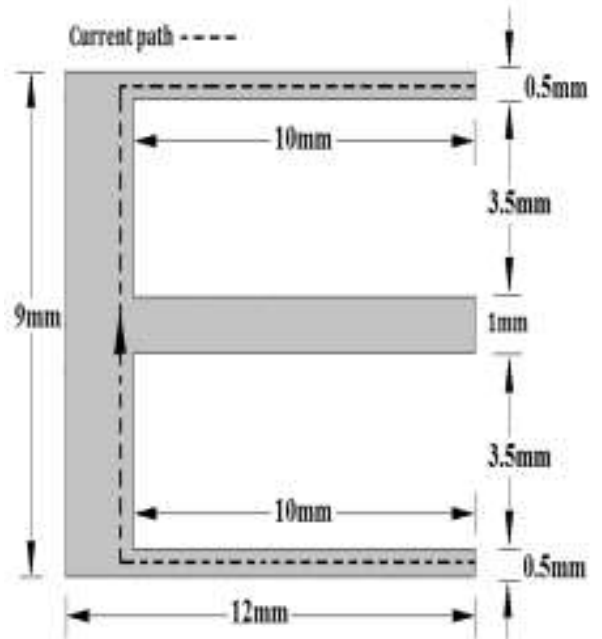

(a)

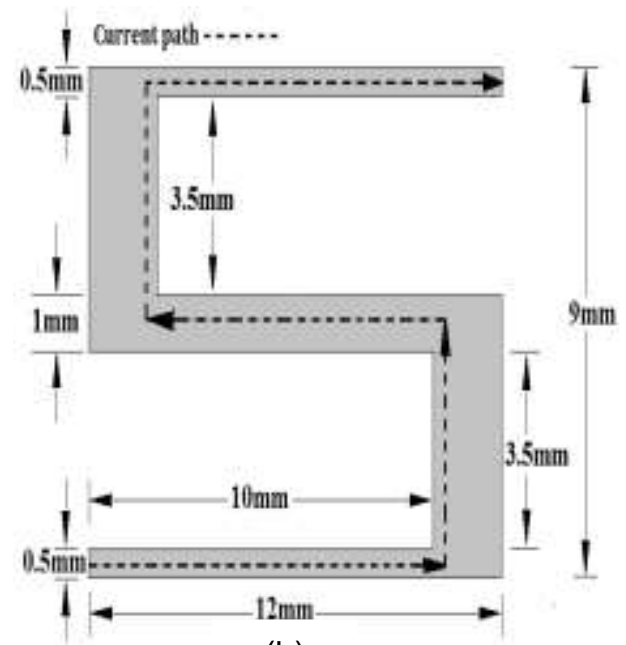

(b)

Figure 13. Current Path for (a) Antenna 2 at $4.4 \mathrm{GHz}$ and (b) Antenna 3 at $3.4 \mathrm{GHz}$

The electrical lengths have been approximated from simulated current distribution and these are assumed as $L_{c 1}$ for Antenna 2 at $4.4 \mathrm{GHz}$ and $L_{c 2}$ for Antenna 3 at $3.4 \mathrm{GHz}$. The $L_{c 1}$ and $L_{c 2}$ are calculated from Figure 13 as follows,

$L_{c 1}=10+3.5+1+3.5+10=28 \mathrm{~mm}$

And $L_{c 2}=10+3.5+0.5+8+0.5+3.5+10=36 \mathrm{~mm}$

The resonant frequencies have been calculated from the following equations,

$f_{1}=\frac{c}{2 L_{C 1}} \sqrt{\frac{2}{1+\varepsilon_{r}}}$ And $f_{2}=\frac{c}{2 L_{C 2}} \sqrt{\frac{2}{1+\varepsilon_{r}}}$

The calculated resonant frequencies for Antenna 2 are $f_{1}=4.24 \mathrm{GHz}$ and for Antenna 3 are $f_{2}=3.3 \mathrm{GHz}$ which are very close to the simulated and measured results.

The simulated and measured radiation patterns for reference antenna, Antenna 2 and Antenna 3 have been shown in Figure 14. The simulated and measured $3 \mathrm{~dB}$ beam width 
of all antennas under study is within $60^{\circ}-70^{\circ}$. The cross polarized field is well below than the co-polarized field.

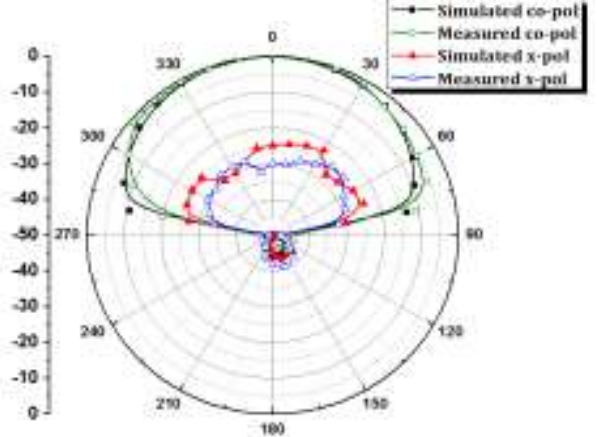

(a)

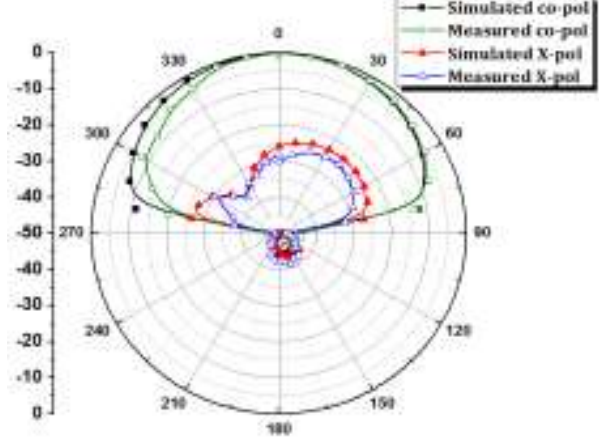

(b)

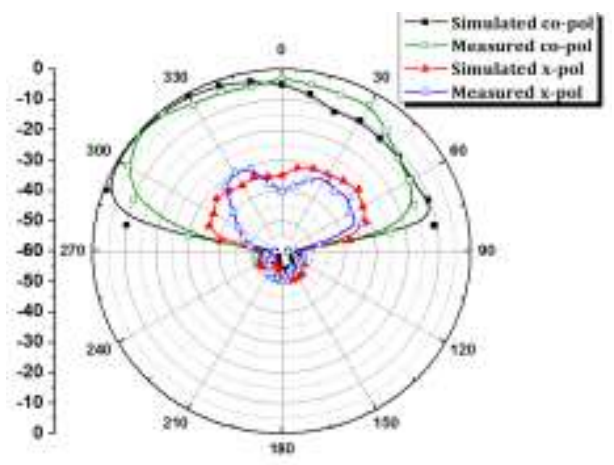

(c)

\section{Figure 14. Radiation Pattern of (a) Reference Antenna at $9 \mathrm{GHz}$, (b) Antenna 2 at $4.6 \mathrm{GHz}$ and (c) Antenna 3 at $3.7 \mathrm{GHz}$}

\section{Conclusion}

In this paper effects of two identical notches parallel to the radiating edges are studied when they are in the same side and opposite side. It has been found that when the notches are in the opposite side the resonant frequency and gain are lower than the resonant frequency and gain when the notches are in the same side. The measured results are well agreed with the simulated values. The equivalent circuits are drawn with the concept of the series and parallel resonant circuit's frequency and gain responses. The resonant frequency can also be found out by taking the total current length path from the current distribution. About $80.2 \%$ size reduction has been achieved by the dual notches in the same non radiating edge and about $87.5 \%$ size reduction is achieved for the dual notches in the opposite non radiating edges. But the gain of the antenna for the dual notches in the opposite non radiating edges falls drastically which may be increased by any gain enhancement method. The proposed antenna may be suitable for INSAT system and WiMAX applications at $4.6 \mathrm{GHz}$ and $3.7 \mathrm{GHz}$ respectively. 


\section{Acknowledgments}

The authors are grateful to the Department of Electronics and Communication Engineering, Central Institute of Technology, Kokrajhar, Assam, India for giving the opportunity and financial support in carrying out this work.

\section{References}

[1] K. L. Wong, "Planer Antennas for Wireless Communications", John Wiley \& Sons Ltd, Hoboken, New Jersey, (2003).

[2] Z. N. Chen, “Antennas for Portable Devices”, John Wiley \& Sons Ltd, West Sussex, England, (2007).

[3] S. Bhunia, D. Sarka, S. Biswas, P. P. Sarkar, B. Gupta and K. Yasumoto, "Reduced Size Small Dual and Multi-Frequency Microstrip Antenna”, Microwave and Opt. Technol. Lett., vol. 50, (2008), pp. 961-965.

[4] S. Bhunia and P. P. Sarkar, "Reduced sized dual frequency microstrip antenna", Indian J. Phys., vol. 83, (2009), pp. 1457-1461.

[5] J. H. Lu and K. L. Wong, "Slot loaded meanedered rectangular microstrip antenna with compact dual frequency operation", Electron Lett, vol. 34, (1998), pp. 1048-1050.

[6] H. Iwasiki, "A circularly polarized small size microstrip antenna with cross slot", IEEE Trans Antenna Propag, vol. 44, (1996), pp. 1399-1401.

[7] J. H. Lu, C. L. Tang and K. L. Wong, "Single feed slotted equilateral triangular microstrip antenna", IEEE Trans Antenna Propag. vol. 47, (1999), pp. 1174-1178.

[8] A. Roy, S. Bhunia, D. Chanda Sarkar, P. P. Sarkar and S. K. Chowdhury, "Compact multi frequency strip loaded microstrip patch antenna with spur lines", Int. J. of Microwave and Wireless Technol., vol. 9, no. 5, (2017), pp. 1111-1121.

[9] A. Roy, S. Bhunia, D. Chanda Sarkar and P. P. Sarkar, "Slot Loaded Compact Microstrip Patch Antenna for Dual Band Operation", Prog., Electromagn. Res. C (PIER C), vol. 73, (2017), pp. 145-156.

[10] R. Azadegan and K. Sarabandi, "A novel approach for miniaturization of slot antennas", IEEE Trans., Antennas Propag., vol. 51, no. 3, (2003), pp. 421-429.

[11] N. Behdadand and K. Sarabandi, "Bandwidth enhancement and further size reduction of a class of miniaturized slot antennas", IEEE Trans. Antennas and Propag., vol. 52, no. 8, (2004), pp. 1928-1935.

[12] B. Ghosh, S. K. Moinul Haque and D. Mitra, "Miniaturization of slot antennas using slit and strip loading”, IEEE Trans. Antennas Propag., vol. 59, no. 10, (2011), pp. 3922-3927.

[13] A. Mishra, P. Singh, N. P. Yadav, J. A. Ansari and B. R. Vishvakarma, "Compact Shorted Microstrip Patch Antenna for Dual Band Operation”, Prog. Electromagn. Res. C, vol. 9, (2009), pp. 171-182.

[14] S. Sharma Shivnarayan and B. R. Vishvakarma, "Analysis of slot-loaded rectangular microstrip patch antenna”, Indian J. of Radio \& Space Phys., vol. 34, (2005), pp. 424-430.

[15] Shivnarayan and B. R. Vishvakarma, "Analysis of notch-loaded patch for dual-band operation", Indian J. of Radio \& Space Phys., vol. 35, (2006), pp. 435-442.

[16] I. J. Bahal and P. Bhartia, "Microstrip antennas", Artech house, (1980).

[17] V. K. Panday and B. R. Vishvakama, "Analysis of an E-shaped patch antenna", Microwave and Opt Technol. Lett., vol. 49, no. 1, (2007), pp. 4-7.

[18] C. A. Balanis, “Advanced Engineering Electromagnetics”, John Wiley \& Sons, (1989), pp. 449-452.

[19] J. A. Ansari, N. P. Yadav, P. Sing and A. Mishra, "Compact half-U slot loaded shorted rectangular patch antenna for broadband operation", Progress In Electromagnetics Research M, vol. 9, (2009), pp. 215226.

[20] U. Chakraborty, A. Kundu, S. K. Chowdhury and A. K. Bhattacharjee, "Compact Dual-Band Microstrip Antenna for IEEE 802.11a WLAN Application", IEEE Antennas and Wireless Propag. Lett., vol. 13, (2014), pp. 407-410.

[21] S. Mathew, M. Ameen, M. P. Jayakrishnan, P. Mohanan and K. Vasudevan, "Compact dual polarised V slit, stub and slot embedded circular patch antenna for UMTS/WiMAX/WLAN applications", Electron. Lett., vol. 52, no. 17, (2016), pp. 1425-1426.

[22] K. Gosaliaand and G. Lazzi, "Reduced Size, Dual-Polarized Microstrip Patch Antenna for Wireless Communications", IEEE Trans. on Antennas and Propag., vol. 51, no. 9, (2003), pp. 2182-2186.

[23] S. C. Gao, L. W. Li, T. S. Yeo and M. S. Leong, "FDTD analysis of a slot-loaded meandered rectangular patch antenna for dual-frequency operation", IEE Proc. Microw. Antenas Propag., vol. 148, no. 1, (2001), pp. 65-71.

[24] A. A. Deshmukh and G. Kumar, "Compact broadband E-shaped microstrip antennas", Electron. Lett., vol. 41, no. 18, (2005), pp. 989-990.

[25] A. K. Sharma, A. Mittal and B. V. R. Reddy, "Slot embedded dual-band patch antenna for WLAN and WiMAX applications", Electron. Lett., vol. 51, no. 8, (2015), pp. 608-609.

[26] C. Liu, S. Xiao, Y. X. Guo, Y. Y. Bai, M. C. Tang and B.-Z. Wang, "Compact circularly-polarised microstrip antenna with symmetric-slit”, Electron. Lett., vol. 48, no. 4, (2012), pp. 195-196.

[27] R. Li and S. Xiao, "Compact slotted semi-circular antenna for implantable medical devices", Electron. Lett., vol. 50, no. 23, (2014), pp. 1675-1677. 
[28] A. A. Deshmukh and K. P. Ray, "Compact Broadband Slotted Rectangular Microstrip Antenna”, IEEE Antennas and Wireless Propag. Lett., vol. 8, (2009), pp. 1410-1413.

[29] X. Ren, S. Gao and Y. Yin, "Compact Tri-Band Monopole Antenna With Hybrid Strips for Wlan/Wimax Applications", Microwave and Opt. Technol. Lett., vol. 57, no. 1, (2015), pp. 94-99.

[30] M. Moosazadeh and S. Kharkovsky, "Compact and Small Planar Monopole Antenna with Symmetrical L- and U-Shaped Slots for WLAN/WiMAX Applications", IEEE Antennas and Wireless Propag. Lett., vol. 13, (2014), pp. 388-391.

[31] M. Moosazadeh, A.M. Abbosh, Z. Esmati, "Design of compact planar ultra wideband antenna with dualnotched bands using slotted square patch and pi-shaped conductor-backed plane", IET Microw. Antennas Propag., vol. 6, Issue. 3, (2012), pp. 290-294.
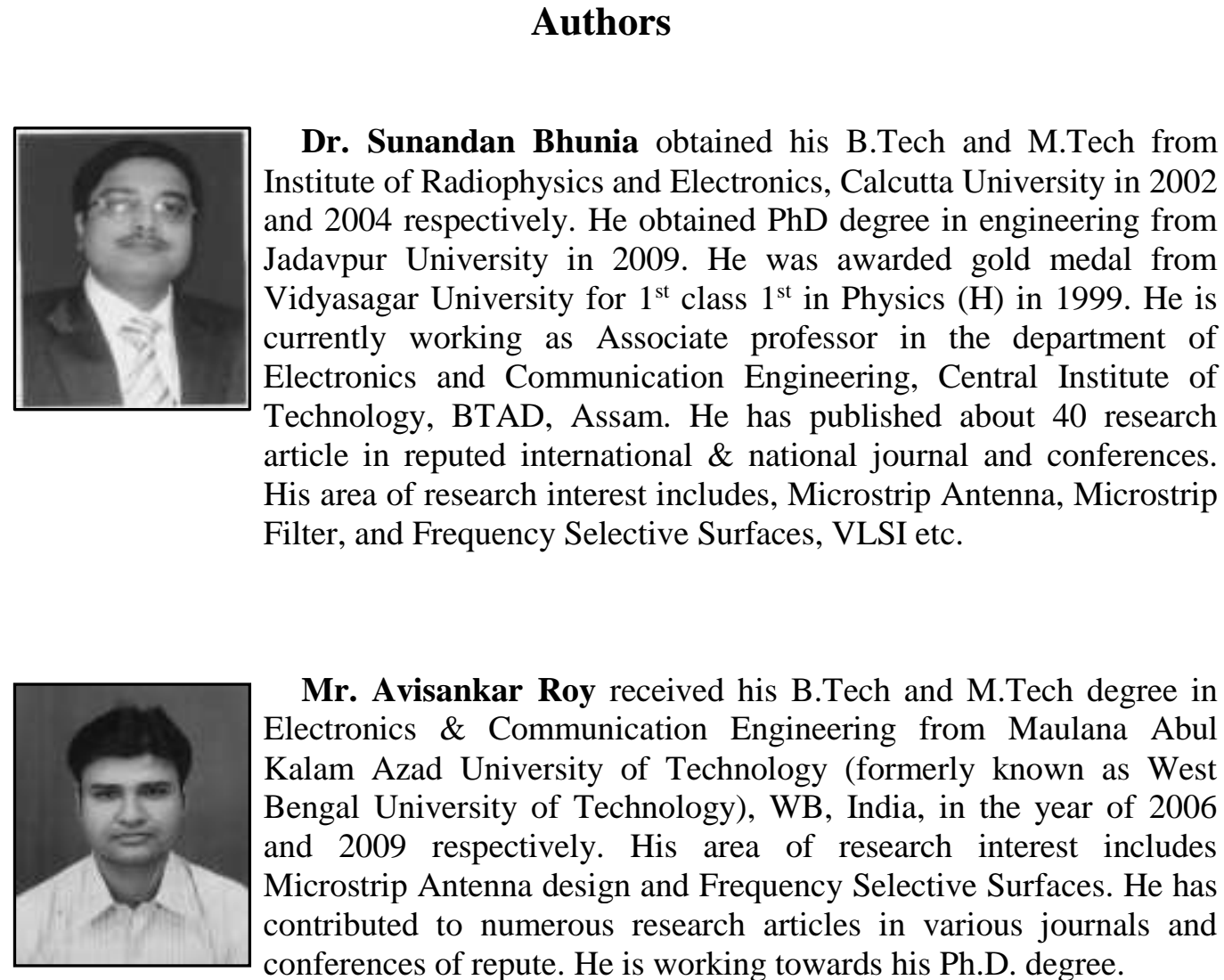

Mr. Avisankar Roy received his B.Tech and M.Tech degree in Electronics \& Communication Engineering from Maulana Abul Kalam Azad University of Technology (formerly known as West Bengal University of Technology), WB, India, in the year of 2006 and 2009 respectively. His area of research interest includes Microstrip Antenna design and Frequency Selective Surfaces. He has contributed to numerous research articles in various journals and conferences of repute. He is working towards his Ph.D. degree.

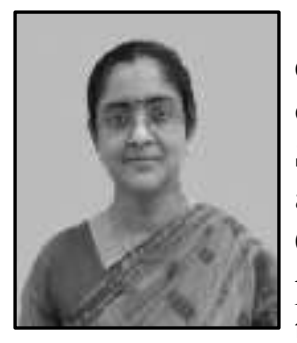

Dr. Debasree Chanda Sarkar was felicitated with a Ph.D in engineering from Jadavpur University in the year 2005. She has obtained her M.E from Bengal Engineering and Science University, Shibpur in the year 1994. She earned her B.E degree in Electronics and Telecommunication Engineering from Bengal Engineering College (Presently known as IIEST, Shibpur) in the year 1991. She is presently working as Scientific Officer (Associate Professor Rank) at the Dept. of Engineering \& Technological Studies, University of Kalyani. Her area of research includes, Microstrip Antenna, Microstrip Filter, Frequency Selective Surfaces, and Artificial Neural Network. She has contributed to numerous research articles in various journals and conferences of repute. 


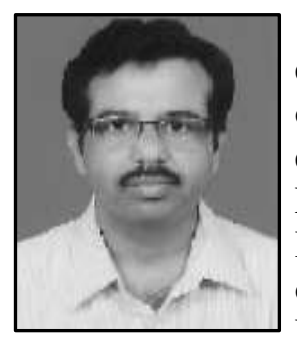

Dr. Partha Pratim Sarkar was felicitated with a $\mathrm{Ph} . \mathrm{D}$ in engineering from Jadavpur University in the year 2002. He has obtained his M.E from Jadavpur University in the year 1994. He earned his B.E degree in Electronics and Telecommunication Engineering from Bengal Engineering College (Presently known as IIEST, Shibpur) in the year 1991. He is presently working in the rank of Professor at the Dept. of Engineering \& Technological Studies, University of Kalyani. His area of research includes, Microstrip Antenna, Microstrip Filter, Frequency Selective Surfaces, and Artificial Neural Network. He has contributed to numerous research articles in various journals and conferences of repute. He is also a life Fellow of IETE and IE(India). 